\title{
Psychometric Properties of Bar-On Emotional Quotient Inventory Youth Version among Omani Children
}

\author{
Tagharid Bint Turki Al Said, Nicola Birdsey, Ian Stuart-Hamilton \\ Department of Psychology, Faculty of Humanities and Social Sciences, University of Glamorgan, United Kingdom
}

Email:ttnfm@yahoo.com

Received: 11 Feb. 2013, Revised: 18 Feb. 2013 , Accepted: 20 Feb. 2013

Published online: 1 Jul. 2013

\begin{abstract}
This study aimed to verify the psychometric properties and norms for the list of Bar-On Emotional Quotient Inventory Youth Version. The total sample of this study consisted of 465 female and male students between 8-10 years $(M=9.25, S D=0.63)$. They were from the governorate of Muscat in the Sultanate of Oman. The items on the list were translated into the Arabic language. To ensure the items' translation validity, the translation was submitted to specialists. Then the data were analyzed through SPSS where the results indicated acceptable validity and reliability indicators. According to the norms; the deviation I.Q. was derived for the crude grades and a psychological profile was prepared to be used with Omani children.
\end{abstract}

Keywords: psychometric properties, Bar-On Emotional Quotient Inventory Youth Version, Bar-On EQ-i: YV (S), Omani children

\section{Introduction}

In the last decade, there has been an increase in the attention given to the subject of Emotional intelligence. This attention is represented by the increasing number of published studies in foreign and Arabic periodicals. One of the reasons behind this interest is that some individuals of intermediate intelligence succeed in their lives, while other individuals struggle and fail in their lives despite being more intelligent (Al-Shayeb, 2010).

The attention given to Emotional Intelligence started at the beginning of the last century. When the movement of studying and measuring it started to appear, Thorndike pointed to emotional intelligence and introduced it as one of the intelligence components that individuals possess, when he was researching social intelligence (Thorndike, 1920).

At the beginning of the Nineties in the 20th century, there appeared a theory of emotional intelligence (Salovey \& Mayer, 1990). Since then this theory has sparked a great deal of attention among researchers and the public. Moreover, the concept of emotional intelligence was considered as a subject which is particularly vital and important in psychology, and to the social sciences in general (Mayer Ciarrochi, \& Forgas, 2001). Books, articles 
and researches that address this subject increased, as well as internet sites. For example, in the Google search engine, the term "emotional intelligence" appears more than a million times. In addition, an integrated curriculum based on this theory has been developed that aims to increase the capacity for emotional intelligence in students (Elias, Hunter, \& Kress, 2001).

The idea of emotional intelligence based on the hypothesis suggests that thinking is better if emotional data are used, where emotions include knowledge which reflects an individual's relations with the world around him. For instance, fear shows that the individual faces a strong threat when he is unable to control the source of that fear. Age usually reflects feeling of injustice. This means that emotions are governed by certain rules and principals (Frijda, 1988). Therefore, there are individual differences in recognizing the information with respect to different life even, understanding this information, using it and organizing it to solve problems (Mayer \& Salovey, 1997).

Although research in emotional intelligence is relatively recent, it may correspond to cognitive intelligence, if not surpass it (Goleman, 1995). Emotional intelligence has its own effect on the individual's personality in various educational, professional and cognitive aspects.

Individual performances in cognitive intelligence tests (non-emotional tests) have been a basic indicator of the judgment process in an individual's level of success for a long time, and as a predictor of future achievement in academic, practical and vocational fields. However, few studies or and researches have pointed out that cognitive intelligence is no longer a good predictor alone in these fields (Cherniss, 2000). If cognitive intelligence and cognitive skills are required in order to gain employment; emotional intelligence offers the professional success for individuals (Goleman, 1995). Goleman $(1998,2001)$ found that cognitive intelligence contributes to success by between $10 \%$ and $-20 \%$ and attributes $80-90 \%$ of this success to other factors.

Alkhadher (2001) summarizes the reasons behind the scientists' attention to emotional intelligence on a limited number of scales that can adequately and successfully measure the mental abilities of individuals in different life situations. Social and professional areas being the most important. Others point out that $10 \%$ and $20 \%$ of variance in the scales of professional success can be attributed to cognitive abilities. While professional success requires further abilities such as emotional and social skills, control of the emotions and self-management. In the professional work field, the researchers concluded that persons of high IQ were not always the best. Whereas giving attention to workers' personal skills in institutions led to the development and increase in skills like self-motivation, perseverance, initiative, flexibility, acceptance of change, the ability to work effectively within a team and withstanding pressure.

The relationship between emotional intelligence and academic achievement is very important in education. Although there are researchers who argue about the difficulty of changing cognitive intelligence (IQ) through with experience and learning, emotional factors can be improved and taught. 


\section{Bar-On Emotional Quotient Inventory}

One of the scales whose use has spread in previous studies is the Bar-On Emotional Quotient Inventory: Youth Version, for adolescents between 7 and 18 years. Several studies have been conducted on this scale to verify its validity and reliability in other environments. The following are some of these studies:

The purpose of Shuler's (2004) study was to contribute to the understanding of emotional intelligence as it occurs in children and adolescents by investigating the psychometric properties (i.e. validity) of the Emotional Quotient Inventory: Youth Version (EQ- i: YV). The validation of this instrument involved the consideration of its relationship to cognitive intelligence, self-report of personality, and parent-report of behaviour. A battery of tests that included a measure of intellectual functioning, an omnibus personality test, a measure of childhood behavioural problems, and the EQ-i: YV was administered to a sample of 143 children ranging in age from 8 to 18 years. A small positive relationship was found to exist between Full Scale IQ and the broadband measure of emotional intelligence. Many significant correlations were obtained between the subtests of the EQi:YV and the omnibus personality test, suggesting a high degree of relationship. Significant correlations were evidenced among the scales of the EQ-i: YV and the measure of childhood behavioural problems (i.e. parent-report of behaviour), but to a much lesser extent than with personality. The EQ- i:YV demonstrated the ability to predict significant emotional disturbance as measured by a clinically elevated score on a broadband measure of emotional difficulties. Lastly, aspects of personality were found to contribute more heavily to the prediction of overall emotional intelligence than did cognitive intellectual functioning.

A study by Al-Qafaas (2007) targeted to verify the Bar-On Emotional Quotient Inventory: Youth Version, used two aspects of psychological adjustment. The sample consisted of 518 male and female 10th grade students (average age was 16). Psychological adjustment for teenagers were applied. Then, Cronbach's alpha coefficient was calculated. The values of $\alpha$ ranged between 0.38-0.63. The correlation between the value of each item and its scope was also calculated. All correlations were statistically significant at 0.01 . The results indicated a statistically significant correlation at the level of 0.01 between Bar-On Emotional Quotient Inventory: Youth Version and the two aspects of psychological adjustment. This result confirms the validity of the Bar-On Inventory in the Arabic environment.

Another study by Al-Milli (2011) aimed at discovering the differences between highly intelligent students and students of average intelligence in the dimensions of emotional intelligence. It also verified the significance of differences in the variables of excellence and gender. To achieve the objectives of the study, the psychometric properties of Bar-On Emotional Quotient Inventory: Youth Version were verified. Then it was applied to a sample of 293 students of average and highly intelligent 10th grade students (average age was 16). Trustees validity was also verified. Matrix correlation between the Dimensions of inventory were calculated (all correlations were significant at the level of 0.01). The reliability was also verified and calculated Half-split (values were between 
0.44-0.730, test re-test (values were between 0.36-0.69), and Cronbach's alpha coefficient (values were between 0.24-073).

\section{Rationale}

In spite of translating the list to suit the Arabic environment in Al-Qafaas' study (2007) and Al-Milli (2011), the two studies use the full form of the list which is about 60 phrases applied to 10th grade students. So the translated lists are not suitable for application to students of the first stage of basic education, who are between 8 and 10 years old. Here came the necessity to this study to verify the psychometric properties and norms of the short form of BarOn Emotional Quotient Inventory which consists of 30 items, and will be used with first stage students of basic education. The significance can be summarized as follows:

1. Previous research provided evidence supporting the use of EQ-i: YV because it is reliable and valid. In addition, the short version was used here on account of time constraints (Austin, Farrelly, Black, \& Moore, 2007).

2. Bar-On Emotional Quotient Inventory: Youth Version can be used in educational, counseling and clinical situations for pupils of first stage of basic education in the governorate of Muscat in the Sultanate of Oman.

3. The inventory can be used to measure the emotional intelligence of Omani children between 8 and 10 years old.

4. The ability to use the psychological profile in drawing a psychological map of emotional intelligence for Omani children, similar to the file developed by Bar-On Profile (refer to Figure 1 in the appendix).

\section{Research questions}

1. What indicators measure the reliability of the Bar-On EQ-i: YV (S) of pupils from grades 1-4 in basic education?

2. What indicators measure the validity of the Bar-On EQ-i: YV (S) of pupils from grades 1-4 in basic education?

3. What are the standards of raw scores for the Bar-On EQ-i: YV (S) for pupils of grades 1-4 in basic education?

\section{Method}

\section{Participants}

A random sample of 465 boys and girls was selected of the pupils in the first level of basic education in the Sultanate of Oman, their ages ranged between 8 and 10 years $(M=9.25, \mathrm{SD}=0.63)$. Table 1 shows the distribution of the study sample by gender and age.

Table 1: Distribution of the sample by gender, and age.

\begin{tabular}{cccc}
\hline Age & Boys & Girls & Total \\
\hline 8 & 24 & 25 & 49 \\
\hline 9 & 126 & 124 & 250 \\
\hline 10 & 81 & 85 & 166 \\
\hline Total & 231 & 234 & 465 \\
\hline
\end{tabular}




\section{Materials}

The Bar-On EQ-i: YV (S) was developed for situations where time is of the essence, where the individual being tested has limited reading or comprehension abilities, where the respondent might be fatigued from a longer set of items, or where multiple administrations of the instrument are desired. The short form was developed using the large normative sample of the EQ-i: YV ( $N=9,172)$. The goal was to develop a scale that would include a sufficient number of items (6 per scale) to reliably assess Intrapersonal, Interpersonal, Stress Management and Adaptability competencies (the sum of which would render a total EQ scale). It was determined that the EQ-i: YV (S) would also include the same 6-item Positive Impression scale included in the EQ-i: YV. Thus, the EQ-i: YV (S) would have 30 items. The 6-item Intrapersonal scale was retained from the long form. For the Interpersonal, Stress Management and Adaptability scales from the long form, the item-pool for each scale was subjected to confirmatory factor analysis, testing a uni-dimensional model. To create 6-item versions of each subscale, only the 6 items with the highest loadings with the latent variables were used (Bar-On \& Parker, 2000).

\section{Procedures}

1. The Bar-On inventory was translated from English into Arabic, and after reviewing the translation and revisions it was presented to a group of specialists in educational psychology, measurement and evaluation, for the purpose of ascertaining the accuracy of the translation, and the validity of the paragraphs and suitability for pupils of the first cycle of basic education in the Sultanate of Oman. The arbitrators agreed on the validity of the translated version although they suggested some amendments; all of these amendments were incorporated. Then the amended version of the inventory was presented along with the original copy to a specialist in English teaching methodology for the purpose of matching the Arabic and English language versions. The specialist agreed with the translation, and did not offer any observations on them.

2. The researcher applied the Bar-On inventory during the month of April 2011.

3. The Bar-On inventory has been corrected using key corrections which come with the test; given scores were (1, $2,3,4$ ) the alternatives to the four (never true for me, seldom true for me, sometimes true for me, often true for me, very often true for me), respectively. Thus, in theory, sub dimensions of scale scores range between 6 and 24, and total IQ scores between 24 and 96.

\section{Statistical analysis}

The raw data file in the SPSS programme and the following statistical methods were used Mean, Standard Deviation, Cronbach's alpha coefficient, Pearson's correlation coefficient, Independent-samples T test, and Deviation I.Q. 


\section{Results}

\section{Item analysis}

The psychometric properties of the items were analyzed and used for selection of items with acceptable properties. The respondents' backgrounds were analyzed first by the SPSS programme. In the item analysis, four indicators were utilized. They were item-reliability index, item-discrimination index.

The item-reliability index was the relationship between each item score and the test total score. The index was calculated by Pearson's correlation coefficients. This index was analyzed by the SPSS program. A moderate coefficient $(r>0.3)$ was expected for item-reliability to indicate an acceptable item (Cohen, 1988).

The item-discrimination index was a t-score, and is the product of the mean difference test of the total score between high scorers and low scorers. To analyze the index, the samples were divided into two groups which were the highest scoring 27 percent and the lowest scoring 27 percent group, as suggested for a large sample size study (Gregory, 2004). The difference of item means between the two groups was examined by a t-test conducted using the SPSS programme. T-test was used as an indicator of a well discriminated item.

\section{Intrapersonal Dimension}

Indicators of reliability coefficient of items of interpersonal dimension ranged( see Table 2 ) between 0.08 and 0.37 . According to Cohen's Criteria (1988) the 12 and 26 items are below the required level. The items discrimination coefficient (calculated t-values) ranged between 7.60 and 17.10 , which are all statistically significant at a level which is not below 0.01 . See Table 2 below.

Table 2: Item-reliability index and Item-discrimination Index for Intrapersonal sub-scale.

\begin{tabular}{clcc}
\hline$\#$ & \multicolumn{1}{c}{ Items } & $\begin{array}{c}\text { Item-reliability } \\
\text { index }\end{array}$ & $\begin{array}{c}\text { Item-discrimination } \\
\text { Index }\end{array}$ \\
\hline 2 & I am good at understanding the way other people & 0.34 & 16.58 \\
& feel. & & 14.09 \\
6 & It is hard to control my anger. & 0.31 & 8.62 \\
12 & I have a temper. & 0.16 & 17.10 \\
14 & I am able to respect others. & 0.37 & 15.21 \\
21 & I fight with people. & 0.37 & 7.60 \\
26 & I try to use different ways of answering hard & 0.08 & \\
& questions. & & \\
\hline
\end{tabular}

\section{Interpersonal Dimension}

Indicators of reliability coefficient of items of Interpersonal dimension ( see Table 3 ) range between 0.31 and 0.37 . According to Cohen's Criteria (1988) all items are acceptable. The items discrimination coefficient (calculated tvalues) ranged between 7.65 and 15.47 , which were all statistically significant. 
Table 3: Item-reliability index and Item-discrimination Index for Interpersonal sub-scale.

\begin{tabular}{clcc}
\hline$\#$ & \multicolumn{1}{c}{ Items } & $\begin{array}{c}\text { Item-reliability } \\
\text { index }\end{array}$ & $\begin{array}{c}\text { Item-discrimination } \\
\text { Index }\end{array}$ \\
\hline 1 & I enjoy having fun. & 0.35 & 11.61 \\
4 & I am happy. & 0.31 & 7.65 \\
18 & I have good thoughts about everyone. & 0.37 & 8.59 \\
23 & I like to smile. & 0.36 & 11.60 \\
28 & It is hard to talk about my deep feelings. & 0.31 & 15.47 \\
30 & I can come up with good answers to hard questions. & 0.36 & 12.96 \\
\hline
\end{tabular}

\section{Stress Management Dimension}

Reliability coefficient indicators of the Stress Management section were ( see Table 4 ) between 0.17 and 0.47. According to Cohen's Criteria (1988), item number 5 was below the required level. The item discrimination coefficient (calculated t-value) ranged between 8.53 and 16.60, which were all statistically significant at a level which is not below 0.01 .

Table 4: Item-reliability index and Item-discrimination Index for Stress Management sub-scale.

\begin{tabular}{llcc}
\hline$\#$ & \multicolumn{1}{c}{ Items } & $\begin{array}{c}\text { Item-reliability } \\
\text { index }\end{array}$ & $\begin{array}{c}\text { Item-discrimination } \\
\text { Index }\end{array}$ \\
\hline 5 & I care what happens to other people. & 0.17 & 8.53 \\
8 & I like everyone I meet. & 0.33 & 14.47 \\
9 & I feel sure of myself. & 0.47 & 15.81 \\
17 & I can talk easily about my feelings. & 0.39 & 16.60 \\
27 & Nothing bothers me. & 0.35 & 15.02 \\
29 & I know things will be okay. & 0.28 & 12.57 \\
\hline
\end{tabular}

\section{Adaptability}

Reliability coefficient indicators of the Adaptability dimension ( see Table 5 ) were between 0.31 and 0.47 . According to Cohen's Criteria (1988) all items were at an acceptable level. The item discrimination coefficient indicators (calculated t-values) ranged between 11.7 and 16.66, which were all statistically significant at a level which is not below 0.01 .

Table 5: Item-reliability index and Item-discrimination Index for Adaptability sub-scale.

\begin{tabular}{llcc}
\hline$\#$ & \multicolumn{1}{c}{ Items } & $\begin{array}{c}\text { Item-reliability } \\
\text { index }\end{array}$ & $\begin{array}{c}\text { Item-discrimination } \\
\text { Index }\end{array}$ \\
\hline 10 & I usually know how other people are feeling. & 0.35 & 13.63 \\
13 & I think that most things I do will turn out okay. & 0.47 & 15.71 \\
16 & It is easy for me to understand new things. & 0.38 & 14.84 \\
19 & I hope for the best. & 0.43 & 16.66 \\
22 & I can understand hard questions. & 0.39 & 14.86 \\
24 & I try not to hurt other people's feelings. & 0.31 & 11.37 \\
\hline
\end{tabular}




\section{Positive Impression Dimension}

Reliability coefficient indicators of Positive Impression dimension ( see Table 6 ) were between 0.26 and 0.34 . According to Cohen's Criteria (1988) items number 15 and 20 were below the required level. The item discrimination coefficient indicators (calculated t-values) range d between 7.82 and 15.03, which were all statistically significant at a level which is not below 0.01 .

Table 6: Item-reliability index and Item-discrimination Index for Positive Impression sub-scale.

\begin{tabular}{clcc}
\hline$\#$ & \multicolumn{1}{c}{ Items } & $\begin{array}{c}\text { Item-reliability } \\
\text { index }\end{array}$ & $\begin{array}{c}\text { Item-discrimination } \\
\text { Index }\end{array}$ \\
\hline 3 & I can stay calm when I am upset. & 0.31 & 10.07 \\
7 & It is easy to tell people how I feel. & 0.32 & 12.46 \\
11 & I know how to keep calm. & 0.30 & 10.49 \\
15 & I get too upset about things. & 0.28 & 7.82 \\
20 & Having friends is important. & 0.26 & 15.03 \\
25 & I try to stick with a problem until I solve it. & 0.34 & 12.88 \\
\hline
\end{tabular}

\section{Correlation Matrix}

The reliability coefficient indicators of Pearson's correlation were between 0.06-0.46 which were all statistically significant at a level which is not below 0.05, except the two sub inventories which are Interpersonal and Stress Management; where it was 0.57 and not statistically significant. Table 7 shows the matrix of Person's correlation coefficient.

Table 7: Correlation Matrix for Bar-On's Sub-scales.

\begin{tabular}{|c|c|c|c|c|c|}
\hline & (A) & (B) & (C) & (D) & (E) \\
\hline (A) Intrapersonal & -- & & & & \\
\hline (B) Interpersonal & $0.23^{* *}$ & -- & & & \\
\hline (C) Stress Management & $0.14^{* *}$ & 0.06 & -- & & \\
\hline (D) Adaptability & $0.27^{* *}$ & $0.38^{* *}$ & $0.12^{*}$ & -- & \\
\hline (E) Positive Impression & $0.32^{* *}$ & $0.37^{* *}$ & $0.17^{* *}$ & $0.46^{* *}$ & -- \\
\hline
\end{tabular}

\section{Reliability}

Cronbach's alpha coefficient was calculated, the coefficients were acceptable compared to the inventory guide (BarOn \& Parker, 2000). Table 8 shows that.

Table 8: Reliability of the Bar-On inventory using a Cronbach's alpha.

\begin{tabular}{lcc}
\hline Sub scales of Bar-On & Number of items & alpha \\
\hline Intrapersonal & 6 & 0.51 \\
Interpersonal & 6 & 0.45 \\
Stress Management & 6 & 0.61 \\
Adaptability & 6 & 0.66 \\
Total EQ & 24 & 0.64 \\
Positive Impression & 6 & 0.51 \\
\hline
\end{tabular}




\section{Norms}

The norms are important because they give raw scores a meaning, and they enable us to explain the scores obtained by the student; furthermore, norms are an essential characteristic of the standardisation process (Gronlund, 2006). The percentile ranks were extracted as norms for the raw scores of the standardisation sample $(n=465)$, as they are the norms most used in intelligence tests generally (Nitko \& Brookhart, 2007), and particularly in the progressive matrices tests (e.g: Bar-On \& Parker, 2000). Percentile ranks are also good indicators of the individual's relative position in his group. Furthermore, percentile ranks are used because they are easy to calculate and their meaning is easily interpreted (Anastasi\& Urbina, 1997). In addition, they are suitable for explaining the ranks of both young and adult people. They may be utilized in educational, clinical and industrial institutes (Thorndike \& Hagen, 1977). The corresponding deviation I.Q was calculated on the basis of adjusted norm scores with an average score (a mean) of 100 and the standard deviation of 15 (Bar-On \& Parker, 2000). The result is shown in Figure 1.

\section{Discussion}

The third study aimed at verifying reliability, validity and norms of the Bar-On Emotional Quotient Inventory: Youth Version. In general, the results indicated that the inventory achieves acceptable psychometric indications. According to the literature of measurement and evaluation on methods of reliability and validity, their different connotations and ways of measuring them, the inventory fulfilled most of these indicators.

Regarding validity, several studies in the related literature discussed three types of validity (Gregory, 2004; Moss, 2007; Sireci, 2007) which are: content validity, criterion-related validity and construct validity. This inventory indicated that cover the three types. Studies such as (Anastasi \& Urbina, 1997) indicated that content validity divides into two parts: face validity and logical validity. In the current study, face validity was verified through the views of a jury to ensure translation validity. All calculated t- values of criterion-related validity were statistically significant between both the highest the lowest groups in all items of the inventory, when calculating discrimination indicator, which is an indicator of criterion-related validity. To ensure construct validity, the correlation between the subinventories of the inventory were verified through calculating the correlation matrix as in table 7 . The results of validity indicates that the inventory measures what it purports to measure, which is $\mathrm{EQ}$, and can be used in clinical and educational fields with children at the first stage of basic education.

To ensure reliability, Cronbach's alpha coefficient was calculated to each sub-scale. In general, results were acceptable comparing them with the previous studies such as (Al-Qafaas, 2007; Al-Milli, 2011). This study is the only one that calculates reliability through Reliability Index indicators. Although some indicators were below the required level according to Cohen's Criteria (Cohen, 1988), these indicators can be compared to the subsequent studies in order to discover and its level and for the purpose of evaluation.

With regard to the norms of the inventory, IQ deviations were calculated for crude grades in each sub-inventory separately, according to the chronological age variable. Norms were summarized in the psychological profile, which is characterised by simplicity and clarity to identify the strengths and weaknesses of each student whose EQ is measured. 


\section{Recommendation}

Bar-On Emotional Quotient Inventory (Youth Version) can be used in educational, counseling and clinical situations for pupils of the first stage of basic education in the governorate of Muscat in the Sultanate of Oman, in addition, the inventory can be used to measure the EQ of Omani children between 8-10 years old. It can be also used the draw a psychological profile of EQ for Omani children between 8-10 years old.

\section{Suggestions}

Based on the results of this study it could be suggested that:

1. Standardizing the Bar-On Emotional Quotient Inventory for the use of Omani students aged between 11-18 years old.

2. Verifying the psychometric properties of the full form of the Bar-On Emotional Quotient Inventory which consists of 60 items, and comparing them with the psychometric properties of the short form which contains 30 items.

\section{Limitation}

The restrictions to generalizability of the results are limited to the students of fourth-grade basic education pupils in the Governorate of Muscat, in the Sultanate of Oman. Using Bar-On scale for measuring EQ may be not suitable for children with reading and language problems, as the test is heavily reliant in language comprehension.

\section{References}

Alkhadher, O. (2001). Emotional Intelligence: the theoretical framework. Paper Presented at the International Social Science and Community Development, College of Social Sciences - Kuwait University, from 10-12 April, (In Arabic).

Al-Milli, S. (2011). Differences in Emotional Intelligence between Gifted and Normal Students in Damascus: A Field Study of the first secondary class students in Damascus city. Damascus University Journal, 27(1-2), 283-320, (In Arabic).

Al-Qafaas, W. K. (2007). Validity of the Bar-On Emotional Quotient Inventory: Youth Version using both sides of the psychological adjustment. College of Education Journal, University of Benha, 17(70), 1-50, (In Arabic).

Al-Shayeb, A. (2010). Psychometric Properties of the Arabic Version of the Wakeman Emotional Intelligence Questionnaire. Jordan Journal of Educational Sciences, 6(1), 53-71, (In Arabic).

Anastasi, A., \& Urbina, S. (1997). Psychological Testing (7th ed.). New Jersey: Prentice Hall.

Austin, E. J., Farrelly, D., Black, C., \& Moore, H. (2007). Emotional intelligence, Machiavellianism and emotional manipulation: Does EI have a dark side? Personality and Individual Differences, 43, 179-189.

Bar-On, R., \& Parker, J. D. A. (2000). The Bar-On Emotional Quotient Inventory: Youth Version (EQ-i:YV) Technical Manual. Toronto, Canada: Multi-Health Systems.

Cherniss, C. (2000). Emotional intelligence: What it is and why it matters. Paper Presented at the Annual Meeting of the Society for Industrial and Organizational Psychology. New Orleans.

Cohen, J. (1988). Statistical Power Analysis for the Behavioral Sciences (2nd ed.). New Jersey: Lawrence Erlbaum. 
Elias, M. J., Hunter, L., \& Kress, J. S. (2001). Emotional intelligence and education. In: J. D. Mayer, J. Ciarrochi, \& J. P. Forgas (Eds.). Emotional intelligence and everyday life: A scientific inquiry. (pp. 133-149). Philadelphia: Psychology Press.

Frijda, N. (1988). The law of emotion. American Psychologist, 43, 349-358.

Goleman, D. (1995). Emotional intelligence. New York: Bantam Books.

Goleman, D. (1998). Working with emotional intelligence. New York: Bantam. Books.

Goleman, D. (2001). An EI-based theory of performance. In C. Cherniss \& D. Goleman (Eds.) The emotionally intelligent workplace (pp. 27-44). San Francisco, CA: Jossey- Bass.

Gregory, R.J. (2004). Psychological testing: history, principals, and applications (4th ed.). Boston: Pearson Education Group, Inc.

Gronlund, N.E. (2006). Assessment of student achievement (8th ed.). Boston: Pearson Education, Inc.

Mayer, J.D., \& Salovey, P. (1997). What is emotional intelligence? In P. Salovey \& D. Sluyter (Eds.), Emotional development and emotional intelligence: Implications for educators (pp. 3-31). New York: Basic Books.

Mayer, J.D., Ciarrochi, J., \& Forgas, J. P. (2001). Emotional intelligence and everyday life: An introduction. In J. Ciarrochi, J. P. Forgas, \& J. D. Mayer (Eds.) Emotional intelligence and everyday life (pp.xi-xviii). New York: Psychology Press.

Moss, P.A. (2007). Reconstructing Validity. Educational Researcher, 36 (8), 470-476.

Nitko, A.J., \& Brookhart, S. (2007). Educational assessment of students. New Jersey: Pearson Education, Inc., Upper Saddle River.

Salovey, P., \& Mayer, J. D. (1990). Emotional intelligence. Imagination, Cognition, and Personality,9(3), $185-211$.

Shuler, C. N. (2004). An analysis of the Emotional Quotient Inventory: Youth Version as a measure of emotional intelligence in children and adolescents. (Unpublished $\mathrm{PhD}$ thesis), The Florida State University.

Sireci, S.G. (2007). On validity theory and test validation. Educational Researcher 36 (8), 477-481.

Thorndike, E. L. (1920). Intelligence and its uses. Harper's Magazine, 140, 227-335.

Thorndike, R. L., \& Hagen, E. P. (1977). Measurement and valuation in psychology and education, (4th ed.). New York: Macmillan Publishing Company. 


\section{Appendix}

\section{BarOn EQ-i:YV (S) Profile for Omani Children}

Name:

Gender: Male Female

Birthdate: Age:

Today's Date:

(Circle One)

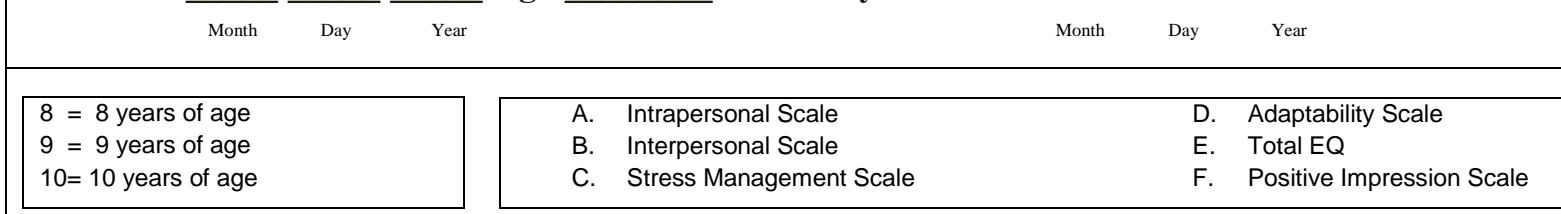

\begin{tabular}{|lllllll}
\hline A & B & C & D & E & F
\end{tabular}

\begin{tabular}{|c|c|c|c|c|c|c|c|c|c|c|c|c|c|c|c|c|c|c|c|}
\hline SS & 8 & 9 & 10 & 8 & 9 & 10 & 8 & 9 & 10 & 8 & 9 & 10 & 8 & 9 & 10 & 8 & 9 & 10 & ss \\
\hline 130 & 23 & 23 & 22 & - & - & - & 22 & 20 & 20 & - & - & - & - & 80 & 81 & - & - & 24 & 130 \\
\hline 129 & 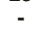 & - & - & - & 24 & - & 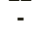 & 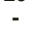 & 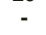 & - & - & - & 82 & - & - & - & - & - & 129 \\
\hline 128 & - & 22 & 21 & - & 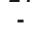 & - & - & - & - & - & - & - & - & - & 80 & - & - & - & 128 \\
\hline 127 & - & - & - & - & - & - & - & 19 & - & - & - & - & 81 & 78 & - & - & 24 & - & 127 \\
\hline 126 & 22 & - & - & - & - & 24 & - & - & 19 & - & 24 & - & - & - & 79 & - & - & - & 126 \\
\hline 125 & - & - & - & - & - & - & - & - & - & - & - & 24 & - & 77 & 78 & 24 & - & 23 & 125 \\
\hline 124 & - & - & & 24 & 23 & - & - & - & - & 24 & - & - & - & $\overline{7}$ & 77 & - & - & - & 124 \\
\hline
\end{tabular}

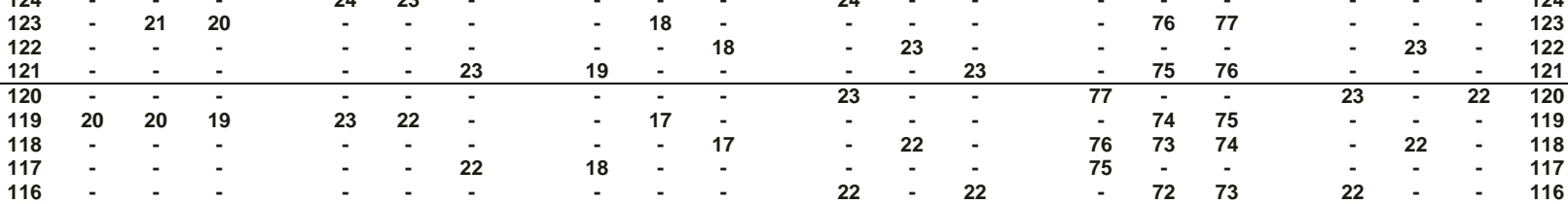

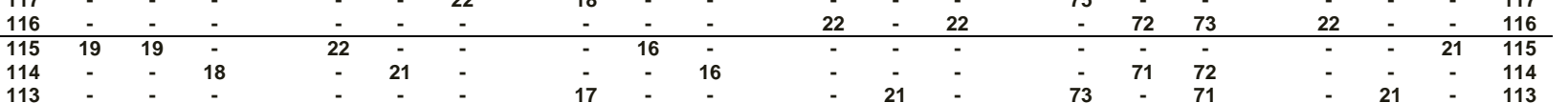

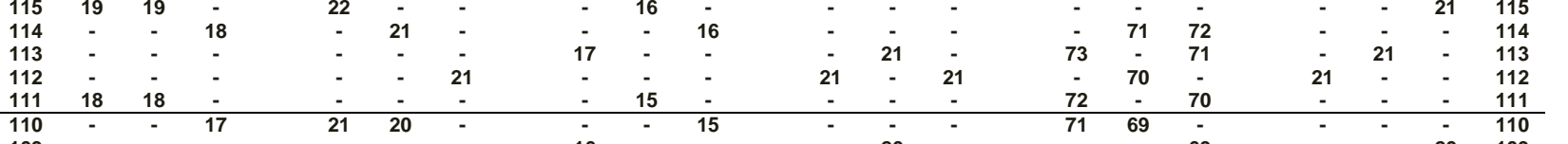

\begin{tabular}{|c|c|c|c|c|c|c|c|c|c|c|c|c|}
\hline 110 & - & - & 17 & 21 & 20 & - & - & - & 15 & - & - & - \\
\hline 109 & - & - & - & - & - & - & 16 & - & - & - & 20 & - \\
\hline 108 & 17 & - & - & - & - & - & - & - & - & 20 & - & 20 \\
\hline 107 & - & 17 & - & - & - & 20 & - & 14 & - & - & - & - \\
\hline 106 & - & - & - & 20 & - & - & - & - & 14 & - & - & - \\
\hline
\end{tabular}

\begin{tabular}{|c|c|c|c|c|c|c|c|c|c|c|c|c|}
\hline 106 & - & - & - & 20 & - & - & - & - & 14 & - & - & - \\
\hline 105 & - & - & 16 & - & 19 & - & 15 & - & - & - & - & - \\
\hline 104 & 16 & - & - & - & - & - & - & - & - & 19 & 19 & 19 \\
\hline 103 & - & - & - & - & - & 19 & - & 13 & - & - & - & - \\
\hline 102 & - & 16 & - & - & - & - & - & - & 13 & - & - & - \\
\hline
\end{tabular}

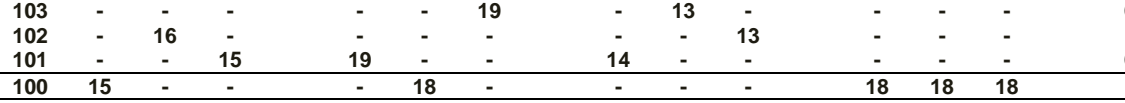

